\title{
Introduction to Part III
}

The empirics of growth and development over the last three decades provide useful insights to contemporary development strategy. Be it the economic experience of India and China or the impact that economic liberalism and globalization has had on the developing world, the dimension that it lends to economic thought and strategy formulation needs to elucidated.

Push the frontiers of thought and we could arrive at a school of thought or proposition that could be a watershed for development strategy. It is an exploration of this possibility that is the focus of the concluding section, Chapters 19-20. 